\title{
Potential of IRMS technology for tracing gamma-butyrolactone (GBL)
}

\author{
François Marclay ${ }^{\mathrm{a}, 1}$, Diego Pazos ${ }^{\mathrm{b}, 1}$, Olivier Delémont ${ }^{\mathrm{b}}$, Pierre Esseiva ${ }^{\mathrm{b}, *}$, Christophe Saudan $^{\mathrm{a}}$ \\ ${ }^{a}$ Swiss Laboratory for Doping Analyses, University Centre of Legal Medecine, Geneva and Lausanne, Centre Hospitalier Universitaire Vaudois and University of Lausanne, \\ Ch. des Croisettes 22, 1066 Epalinges, Switzerland \\ ${ }^{\mathrm{b}}$ Institut de Police Scientifique, Ecole des Sciences Criminelles, Université de Lausanne, Batochime, 1015 Lausanne-Dorigny, Switzerland
}

\section{A R T I C L E I N F O}

\section{Article history:}

Received 19 August 2009

Received in revised form 3 December 2009

Accepted 8 December 2009

Available online 6 January 2010

\section{Keywords:}

Drug of abuse

Isotope ratio mass spectrometry

Gamma hydroxy butyric acid

Gamma butyrolactone

\begin{abstract}
A B S T R A C T
Popularity of $\gamma$-hydroxybutyric acid (GHB) is fairly stable among drug users, while the consumption of its chemical precursor, $\gamma$-butyrolactone (GBL), is a growing phenomenon. Although conventional analytical methods allow to detect this substance in various matrices, linking a trace and a source is still a difficult challenge. However, as several synthesis pathways and chemical precursors exist for the production of GBL, its carbon isotopic signature may vary extensively. For that purpose, a method has been developed to determine the carbon isotopes content of GBL by means of gas chromatography/combustion/isotope ratio mass spectrometry (GC/C/IRMS).

The $\delta^{13} \mathrm{C}$-values of 19 bulk samples purchased worldwide were in the range from -23.1 to $-45.8 \%$ ( $\mathrm{SD}<0.3 \%$ ). Furthermore, testing on the purification of GBL by distillation has not been found to be consistent with such a large range of $\delta^{13} \mathrm{C}$-values, which are likely to result from the isotopic composition of the organic precursors used to produce GBL together with the kinetic isotope effect associated with the synthesis routes. Finally, inter- and intra-variability measurements of the $\delta^{13} \mathrm{C}$-values demonstrated the high potential of IRMS for discriminating between seizures of GBL and for source determination.
\end{abstract}

๑ 2009 Elsevier Ireland Ltd. All rights reserved.

\section{Introduction}

The demand for $\gamma$-butyrolactone (GBL) has increased in the last decade, mainly as a chemical intermediate to manufacture polymers, but also as a biodegradable degreaser or paint remover [1]. In 2002, the domestic production in the USA was estimated at 80,000 tons per year [2]. The total capacity of GBL manufacturing in China was reported in 2006 to be around 50,000 tons per year [3]. As illustrated in Fig. 1, several chemical intermediates may be potentially converted into GBL at the industrial level. The major portion of GBL is currently being produced via the dehydrogenation of 1,4-butanediol (1,4-BD) [4-6], which is manufactured from the reaction of acetylene with formaldehyde; this reaction is known as the Reppe process [7]. New manufacturing routes of GBL are based on the two-stage hydrogenation of economically attractive raw materials such as dimethyl maleate [8] or maleic anhydride [9-11]. Tetrahydrofurane can also be used as a precursor to synthesize GBL following a single oxidation step [12].

Recreative use of $\gamma$-hydroxybutyric acid (GHB) and to a lesser extent GHB-facilitated sexual assaults ('date rape') is a relatively

\footnotetext{
* Corresponding author at: Institut de Police Scientifique, 1015 LausanneDorigny, Switzerland. Tel.: +41 216924652; fax: +41 216924605.

E-mail address: Pierre.esseiva@unil.ch (P. Esseiva).

1 These authors contributed equally to this work.
}

recent and stable phenomenon among European countries [13,14]. However, recent surveys indicate that consumption of its chemical precursors, namely GBL and 1,4-BD, is a growing trend among drug users due to several promoting factors [15]. Starting with these materials, the synthesis of GHB is rather simple and, most remarkably, these precursors exhibit a rapid conversion into GHB by peripheral lactonase upon direct oral consumption [2,1618]. Moreover, both GBL and 1,4-BD would hardly be regulated under a national or an international legislation as they are important and common industrial solvents used in large quantities in the synthesis of plastics and polymers [13,19]. The lack of control coupled with the availability of these substances on the internet for a relatively cheap price increase the popularity of GHB, GBL and 1,4-BD consumption. Therefore, there is a need to develop analytical means to assist law enforcement agencies disrupt the use and trafficking of GHB and its precursors.

In forensic cases, the presence of GHB or precursors is investigated in items seized at the premises, in the form of drug samples or spiked beverages, but also as biological samples (urine or blood) collected from drug users or sexual assault victims. Although these substances may be detected by conventional analytical methods, any linkage between trace and source is difficult to ascertain. However, as these substances can be synthesized through many different routes using a diversity of chemicals, variations in their stable isotopes content may be potentially observed. In that respect, several investigations of 


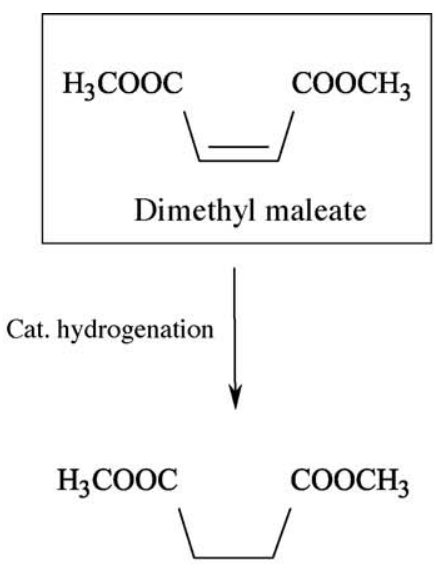

Dimethyl succinate
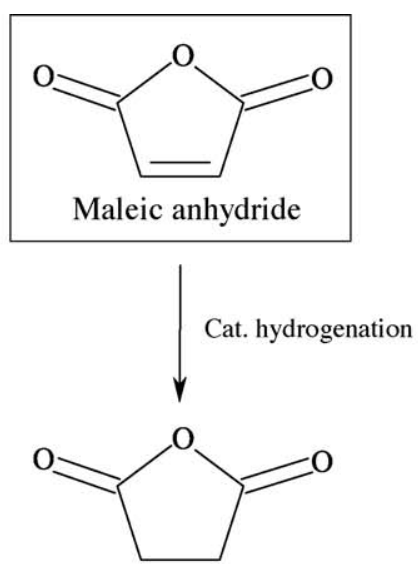

Succinic anhydride

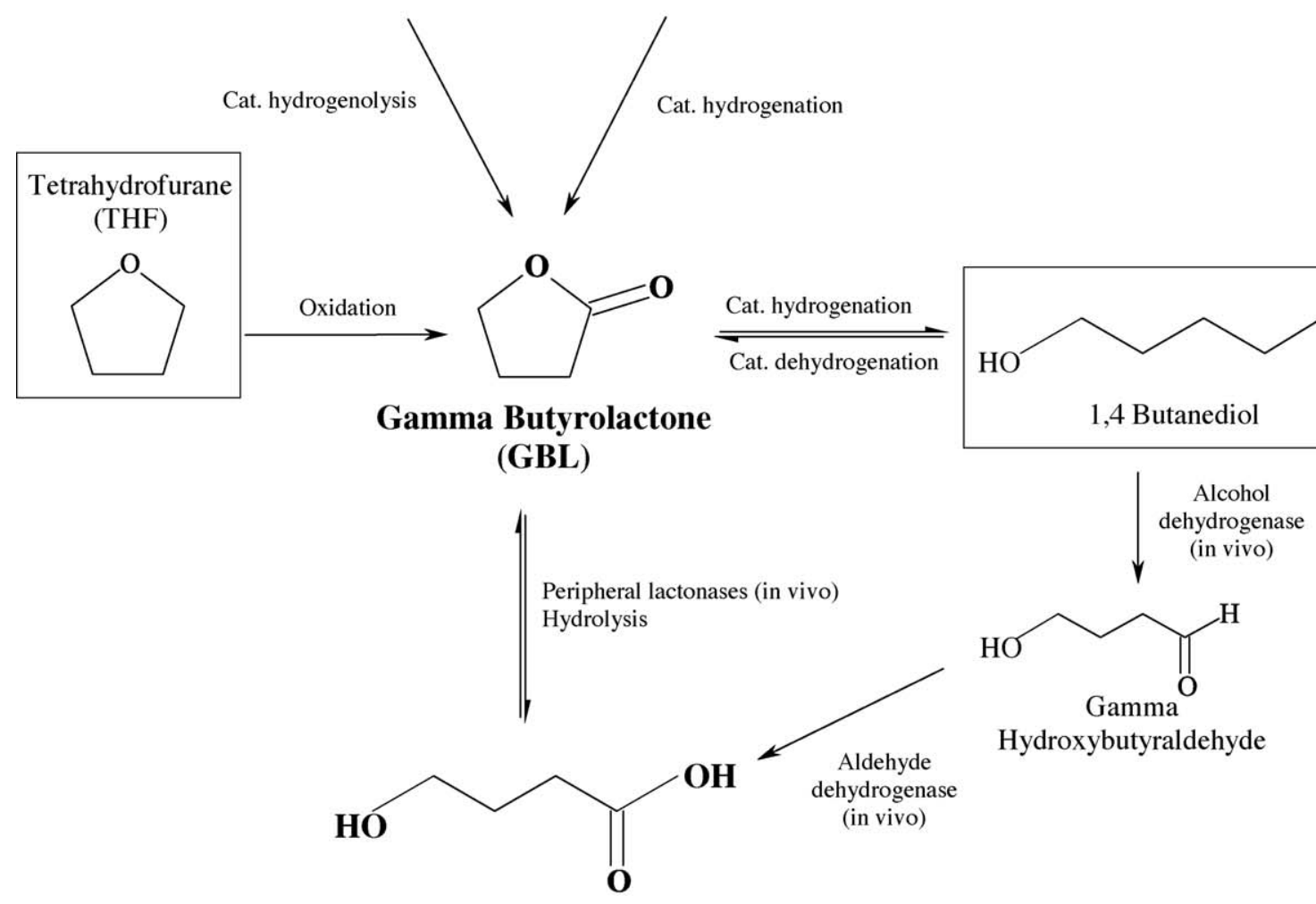

\section{Gamma hydroxybutyric acid (GHB)}

Fig. 1. Structures and synthesis pathways of synthetic precursors of $\gamma$-butyrolactone.

stable isotopes have been conducted to assist in determining the manufacturing source of illicit synthetic drugs such as amphetamine type stimulants based molecules [20].

In the present study, an appropriate and robust gas chromatography/combustion/isotope ratio mass spectrometry $(\mathrm{GC} / \mathrm{C} /$ IRMS) method has been developed and tested for the characterization of GBL samples. Then, the variability in the carbon isotopic compositions between samples of GBL purchased from different chemical providers and internet retailers of various countries in the world has been studied. The distillation effect has also been evaluated as it takes place in the production of GBL and thus may possibly affect the isotope ratio value. Finally, the discriminating ability of IRMS to infer the source of GBL samples will be discussed. This work provides a baseline for future studies and some explanation to understand the variations in the carbon isotope composition of GBL.

\section{Materials and methods}

\subsection{Chemicals}

Dichloromethane ( $\geq 99.9 \%$ ) was purchased from Merck (Darmstadt, Germany). $\gamma$-Butyrolactone (GBL) was purchased from Fluka ( $\geq 99.0 \%$, Lot 001363070 , Buchs, Switzerland), Sigma ( $\geq 99.0 \%$, Lot 087K3521, Buchs, Switzerland), Lipomed ( $>99.0 \%$, Lot 823.1B0.1L5, Arlesheim, Switzerland) and Wako ( $>99.0 \%$, Lot PEN6670, Osaka, Japan). $\varepsilon$-Caprolactone ( $\geq 99.0 \%$, Lot 1256826$)$ was obtained from Fluka (Buchs, Switzerland). Helium (Quality 60, >99.9999\%) and carbon dioxide gas (Quality 40, $>99.99 \%$ ) were purchased from Carbagas (Domdidier, Switzerland). Tetradecanoic acid methyl ester (C14:0, \#14M, $\mathrm{C}_{15} \mathrm{H}_{30} \mathrm{O}_{2}, \delta^{13} \mathrm{C}=-29.98 \pm 0.02 \%,>99.0 \%$ ) was obtained from Arndt Schimmelmann (Indiana University, Department of Geological Sciences, Biogeochemical Laboratories, 1001 East 10th Street, Bloomington, IN, USA). 
Bulk GBL was purchased from different internet retailers: Alloycleaner (\#1, London, United Kingdom), CleanMpower (\#2, Bytom, Poland), Cleanstar24 (\#3, Taarnawa Dolna, Poland), Everchem (\#4, China), GBL24 (\#5, Bialystok, Poland), GBL Cleaner (\#6, Uden, Netherlands), Liquidsoap (\#7, Coco Islands, United Kingdom), Multicleaner (\#8, Nijmegen, Netherlands), Shine\&Bright (\#9, Nijmegen, Netherlands), Eastar Chem Industrial Corp. (\#10, China), Nanjing KaiKai Technology Co. Ltd. (\#11, China), Taizhou Synhwa PharmaChem Co. Ltd. (\#12, China) and two different batches from Anhui Huaxing Chemical Industry Co. Ltd. (\#13 and 14, China) ordered at 6 months interval.

\subsection{Sample preparation}

In a $10 \mathrm{~mL}$ glass tube, $150 \mu \mathrm{L}$ of $\varepsilon$-caprolactone (Internal Standard, $20 \mu \mathrm{g} / \mathrm{mL}$ in dichloromethane) and $50 \mu \mathrm{L}$ of tetradecanoic acid methyl ester (Isotope Calibrator, $10 \mu \mathrm{g} / \mathrm{mL}$ in dichloromethane) were added to $100 \mu \mathrm{L}$ of $\mathrm{GBL}(100 \mu \mathrm{g} / \mathrm{mL}$ in dicholoromethane). After vortex-mixing for $5 \mathrm{~s}$, the solution was transferred to an auto-sampler vial with a $300 \mu \mathrm{L}$ insert for both GC-MS and GC/C/IRMS analyses.

\subsection{Description of the distillation apparatus}

A standard distillation design was employed for the study of the carbon isotope fractionation of GBL during evaporation. An aliquot of $100 \mathrm{~mL}$ GBL was introduced into a $250 \mathrm{~mL}$ two-neck round-bottom flask connected to a distillation head. A thermometer was connected to the two-neck round-bottom flask above bulk GBL to record the temperature of the escaping vapor. The distillation head was composed of a 15-cm long neck at the top of which a standard thermometer was fixed to follow the temperature of the vapor during distillation and a lateral condenser whose inner heat exchange tube is $25 \mathrm{~cm}$ long. The condenser was cooled with water at ambient temperature $\left(\sim 23^{\circ} \mathrm{C}\right)$. Four $50 \mathrm{~mL}$ round-bottom flasks were connected to the condenser using a distillation receiver. A heating mantle was used to slowly heat the bulk sample to a temperature of $204^{\circ} \mathrm{C}$, corresponding to the boiling point of GBL. Complete distillation was performed within $2 \mathrm{~h}$ and allowed to collect four distillate fractions of $25 \mathrm{~mL}$ each. For comparison purposes, three distillations were performed for each bulk GBL and each distillate fraction was measured in triplicate by means of GC/C/IRMS.

\subsection{GC/C/IRMS analysis}

The carbon isotope measurements were performed on a Delta V Plus IRMS system (ThermoFisher Scientific, Bremen, Germany) coupled to a Trace GC Ultra Gas Chromatograph via a GC-C/TC III interface (ThermoFisher Scientific, Bremen, Germany). The samples were injected via a TriPlus ${ }^{\mathrm{TM}}$ autosampler (ThermoFisher Scientific, Bremen, Germany). The mass spectrometer consisted of an electron impact source held at $3.0 \mathrm{kV}$ acceleration voltage for $\mathrm{CO}_{2}$ gas, a magnet and three Faraday collectors for measurement of the ions at $m / z 44,45$ and 46.

Chromatographic separations were achieved on a DB-17MS capillary column (30 $\mathrm{m} \times 0.25 \mathrm{~mm}$ i.d., $0.25 \mu \mathrm{m}$ film thickness) from J\&W Scientific (Folsom, CA, USA). Helium was used as carrier gas with a constant flow of $1.2 \mathrm{~mL} / \mathrm{min}$. The GC injection port, combustion oven and reduction oven temperatures were set to $280{ }^{\circ} \mathrm{C}, 940{ }^{\circ} \mathrm{C}$ and $600{ }^{\circ} \mathrm{C}$, respectively. Reference carbon dioxide gas pulses $(20 \mathrm{~s}$ durations) were introduced at five different times during the course of the chromatographic separation. Regarding the analysis of the samples containing GBL, the internal standard (IS) and the internal calibrator (IC), the oven temperature was increased from $50^{\circ} \mathrm{C}(3 \mathrm{~min})$ to $150^{\circ} \mathrm{C}$ at $20^{\circ} \mathrm{C} / \mathrm{min}$, then to $300^{\circ} \mathrm{C}$ at $30^{\circ} \mathrm{C} / \mathrm{min}$, and maintained at the final temperature for $3 \mathrm{~min}$. The volume of injection was $1 \mu \mathrm{L}$ and the samples were injected in the splitless mode $(1.50 \mathrm{~min})$. Oxidation of the combustion reactor was performed over $1 \mathrm{~h}$ after every batch of 30 samples.

The symbol $\delta$ is the standard notation for expressing carbon isotope ratios. It is defined as parts per thousand deviation of isotopic compositions from that of Vienna Pee Dee Belemnite (VPDB) and is calculated according to [21]:

$\delta^{13} \mathrm{C}(\%)=\frac{\left({ }^{13} \mathrm{C} /{ }^{12} \mathrm{C}\right)_{\text {sample }}-\left({ }^{13} \mathrm{C} /{ }^{12} \mathrm{C}\right)_{\text {standard }}}{\left({ }^{13} \mathrm{C} /{ }^{12} \mathrm{C}\right)_{\text {standard }}} \times 1000$

Acquisition and evaluation of the GC/C/IRMS data were performed with the ISODAT 2.5 software (ThermoFisher Scientific, Bremen, Germany).

\subsection{GC/MS analysis}

Prior to GC/C/IRMS analysis, identification of the substance was ensured by GC chromatographic retention time in agreement within $1 \%$ of the retention time of reference material analysed in the same batch and by measurement of full EI MS spectrum between $\mathrm{m} / \mathrm{z} 40$ and 300 with an acceptable maximum tolerance edited in a technical document [22]. The diagnostic ions selected for identification of each compound were the following: GBL $(\mathrm{m} / z 56$ and 86$), \varepsilon$-caprolactone $(\mathrm{m} / z 55,75,84$ and 114) and tetradecanoic acid methyl ester $(m / z 55,74,87,143,199$ and 242).

The GC/MS analyses were performed on a Hewlett-Packard 5890 Series II Plus gas chromatograph (HP Analytical Division, Waldbronn, Germany) equipped with a HP 7673 auto-sampler and coupled with a HP 5971 mass selective detector (MSD). GC separation was achieved on a DB-17MS capillary column $(30 \mathrm{~m} \times 0.25 \mathrm{~mm}$ i.d.,
$0.25 \mu \mathrm{m}$ film thickness) from J\&W Scientific (Folsom, CA, USA). Helium was used as carrier gas with a constant flow of $0.8 \mathrm{~mL} / \mathrm{min}$ and at the initial column head pressure of 15 psi. For a robust identification of the target compounds, the GC operating conditions were identical for both GC-MS and GC/C/IRMS analyses. The oven temperature was increased from $50{ }^{\circ} \mathrm{C}(3 \mathrm{~min})$ to $150{ }^{\circ} \mathrm{C}$ at $20^{\circ} \mathrm{C} / \mathrm{min}$, then to $300{ }^{\circ} \mathrm{C}$ at $30^{\circ} \mathrm{C} / \mathrm{min}$, and maintained at the final temperature for $3 \mathrm{~min}$. Injections of samples $(1 \mu \mathrm{L})$ were made at $280{ }^{\circ} \mathrm{C}$ in the splitless mode. EI mass spectra were recorded with the instrument tuned by continuous scanning in the 40-300 amu range at an ionization potential of $70 \mathrm{eV}$.

\subsection{Data treatment and analysis}

The $\delta^{13} \mathrm{C}$-values were analysed statistically using S-PLUS ${ }^{\mathbb{B}} 7.0$ for Windows. For distribution testing, a Kolmogorov-Smirnov test of normality has been employed. Equality of the variances was assessed using a Levene test. Then, statistical differences among groups were tested using the two-sample $t$-test, with $p<0.05$ considered statistically significant.

The evaluation of the overlapping zone between the inter-variability and the intra-variability of the distribution $\delta^{13} \mathrm{C}$-values was performed by studying the behaviour of the ROC (receiver operating characteristic) curves [23].

\section{Results and discussion}

From the early 1990s, extended research has been conducted on drug profiling in the area of analytical method development and statistical data treatment. Methodologies have been established for the comparison of illicit drug seizures in an intelligence-led perspective using large databases [24]. These methods mainly use $\mathrm{GC} / \mathrm{MS}$ for the analysis of samples in order to obtain intelligence information.

Basically, some drugs are produced through a number of different routes. Therefore, the organic impurities profile which will be influenced by the precursors and chemicals can provide valuable information to assess the link between drug seizures, production batches and trafficking routes [25-27]. Regarding profiling of GBL, it appears that this approach will not be effective as this chemical is manufactured at high purity level (>99\%). GCMS analysis of the samples purchased from different internet retailers and obtained from police seizures confirmed indeed the presence of impurities at trace level. Alternatively, the determination of differences in the carbon isotope ratio of GBL by means of IRMS was found to be a more promising methodology to tackle the links between GBL samples. Valuable use of stable isotope profiles has already been assessed in order to gain intelligence through forensic analysis, for instance for the determination of the geographic origin of drugs [28], or for linking samples of drugs [29] or black powder [30].

Based on previous work, GBL may be analysed by means of GC/C/IRMS using a moderately polar column and hence does not require a chemical modification to provide acceptable chromatographic characteristics [31]. In that study, it is worth to note that each sample preparation was spiked with $\varepsilon$ caprolactone and tetradecanoic acid methyl ester. Tetradecanoic acid methyl ester was added as a standard of known isotopic composition to calibrate the target compounds, while $\varepsilon$ caprolactone, a lactone displaying slightly different chromatographic retention than GBL, was used as an internal standard compound to test for potential mass discrimination during the course of GC/C/IRMS analyses [32]. An example of a GC/C/IRMS chromatogram of GBL, $\varepsilon$-caprolactone and tetradecanoic acid methyl ester is shown in Fig. 2. Reference carbon dioxide gas pulses (20 s width) were introduced five times during the chromatographic runs to check for IRMS stability.

Prior to the determination of the carbon isotopic ratio of the lots of GBL, analysis of different quantities of GBL from the same batch was performed to define the linear response of the IRMS. This parameter is crucial as it might be that accuracy of GC/C/IRMS is significantly affected when signal intensity is outside the linearity range [33]. Typically, it resulted in stable $\delta^{13} \mathrm{C}$-values $(0.09 \% / \mathrm{V})$ for 


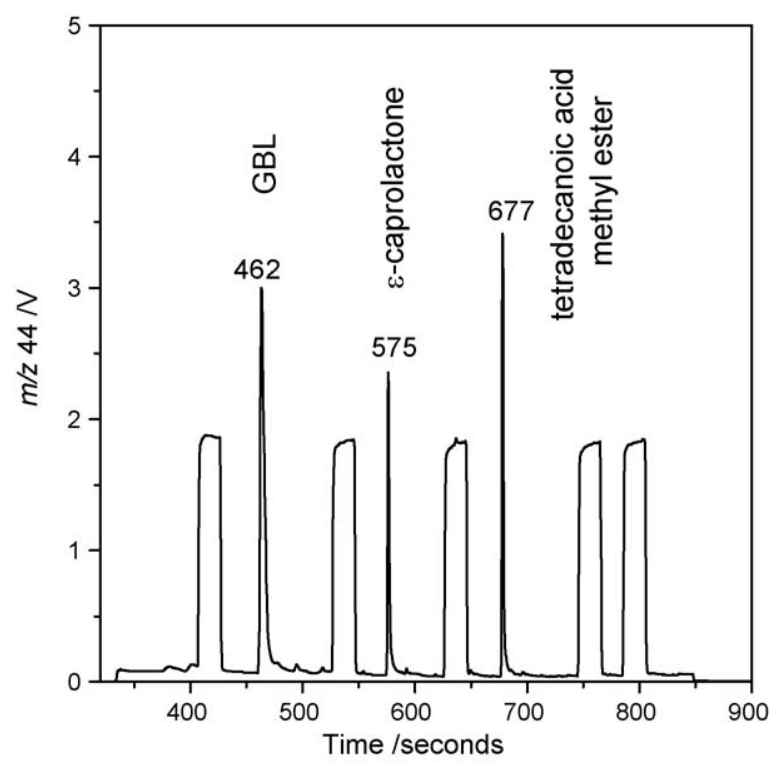

Fig. 2. GC/C/IRMS chromatogram $(m / z 44)$ of GBL, $\varepsilon$-caprolactone and tetradecanoic acid methyl ester. The square-topped peaks represent pulses of $\mathrm{CO}_{2}$ reference gas.

the signal intensities between 0.5 and $4 \mathrm{~V}$ on the $\mathrm{m} / \mathrm{z} 44$ channel corresponding to injected amounts of 1 and $10 \mathrm{ng}$, respectively.

Table 1 lists the carbon isotopic data of GBL samples obtained from chemical providers and internet retailers (GBL\#1-14). The $\delta^{13} \mathrm{C}$-values of these GBL samples ranged from -23.1 to $-45.8 \%$, and were associated with standard deviations lower than $0.3 \%$ of triplicate analysis. The stability of IRMS measurement during the chromatographic separation was verified by the standardon-off tests ( $\mathrm{SD}<0.21 \%$ for 5 reference $\mathrm{CO}_{2}$ pulses). Furthermore, reproducible $\delta^{13} \mathrm{C}$-values for $\varepsilon$-caprolactone (IS) were obtained (mean $\delta^{13} \mathrm{C}$-value $=-26.15 \%$, SD $=0.14 \%, \quad n=114$ ), thereby enabling a $95 \%$ confidence interval as a run acceptance criteria. Noteworthy, distribution of the $\delta^{13} \mathrm{C}$-values of the internal standard showed no significant deviation from Gaussianity $(p>0.05)$ as revealed by the Kolmogorov-Smirnov test. The GBL samples were analysed again in triplicates 6 months later and did not show significant deviations from the mean $\delta^{13} \mathrm{C}$-values and related SD listed in Table 1 . Finally, all $\delta^{13} \mathrm{C}$ - values of the IS were comprised in the confidence interval established previously (two-sample $t$-test). The repeatability of the ${ }^{13} \mathrm{C}$ measurements is of major importance in a forensic context in order to create and maintain a carbon isotope ratio database of GBL samples.

A relatively large range of $\delta^{13} \mathrm{C}$-values has been determined in that study for the GBL samples purchased from various internet retailers and chemical providers. A variation of $-23 \%$ in the $\delta^{13} \mathrm{C}$ values of GBL is equivalent to a difference in the ${ }^{13} \mathrm{C}$ isotope abundance of 0.025 at.\%. Scanning MS in selected ion monitoring (SIM) might only achieve reliable analyses of isotopic composition at natural abundance level of 0.1 at.\% [34,35]. Hence, it would not be conceivable for our purpose to perform carbon isotope analyses using a conventional mass spectrometer.

GBL production may include a purification step, generally a distillation, to obtain the product in a pure form [9]. Therefore, a possible isotope fractionation due to the thermodynamic isotope effect should also be considered [20]. Distillation of solvent such as methanol, chloroform and benzene were found to lead to a slight depletion of ${ }^{13} \mathrm{C}$ between the original vapor phase collected and consecutive fractions [36]. A comprehensive explanation of these results at the molecular level was reported subsequently [37]. To assess the magnitude of isotopes fractionation by distillation of GBL, IRMS analysis of GBL collected over consecutive distillates fractions was performed. For instance, distillations of $100 \mathrm{~mL}$ bulk GBL\#11 resulted in a slight depletion of ${ }^{13} \mathrm{C}$ between consecutive $25-\mathrm{mL}$ fractions ( $-27.7 \%$ for the first distillate versus $-28.5 \%$ for the last one). Based on these results, purification by means of distillation will not affect the $\delta^{13} \mathrm{C}$-values dramatically, at least it may not provide an explanation for the wide range of $\delta^{13} \mathrm{C}$-values reported in this study.

On the basis of the current knowledge, it can be assumed that the broad range of $\delta^{13} \mathrm{C}$-values for GBL is probably the consequence of the variability in the carbon isotope composition of the organic precursors which will be conserved through to the product GBL. To test this hypothesis, batch-to-batch variations were assessed for bulk GBL (GBL\#13-14) obtained from an industry using the Reppe process to manufacture 1,4-BD. As main outcome, statistical analysis did not reveal any evidence against the assumption that the mean $\delta^{13} \mathrm{C}$-values were equal. Hence, it is likely that the $\delta^{13} \mathrm{C}$-values of GBL were inherited in that case from those of acetylene and formaldehyde, two precursors which served to synthesize 1,4-BD in a first

Table 1

$\delta^{13} \mathrm{C}$-values of GBL samples obtained from chemical providers and internet retailers (GBL\#1-14). Both series of analyses were performed at 6 months interval.

\begin{tabular}{|c|c|c|c|c|c|c|}
\hline \multirow[t]{2}{*}{ Type } & \multirow[t]{2}{*}{ Sample id } & \multirow[t]{2}{*}{ Country of purchase } & \multicolumn{2}{|c|}{1 st series of analyses } & \multicolumn{2}{|c|}{ 2nd series of analyses } \\
\hline & & & $\delta^{13} \mathrm{C}$ value/\%o & $\mathrm{SD} / \%$ & $\delta^{13} \mathrm{C}$ value/\%o & $\mathrm{SD} / \%$ \\
\hline \multirow[t]{5}{*}{ Standard } & Fluka & Switzerland & -45.1 & 0.06 & -44.9 & 0.14 \\
\hline & Lipomed & Switzerland & -31.7 & 0.12 & -31.6 & 0.07 \\
\hline & Riedel de Haen & Germany & -36.4 & 0.12 & -36.3 & 0.10 \\
\hline & Sigma & Switzerland & -35.1 & 0.08 & -35.1 & 0.12 \\
\hline & Wako & Japan & -26.0 & 0.10 & -26.0 & 0.12 \\
\hline \multirow[t]{14}{*}{ Internet retailer } & $\# 1$ & UK & -24.1 & 0.09 & -24.2 & 0.07 \\
\hline & $\# 2$ & Poland & -45.5 & 0.02 & -45.5 & 0.06 \\
\hline & \#3 & Poland & -45.8 & 0.05 & -45.8 & 0.14 \\
\hline & $\# 4$ & China & -30.0 & 0.05 & -30.0 & 0.12 \\
\hline & \#5 & Poland & -45.5 & 0.18 & -45.5 & 0.05 \\
\hline & \#6 & Netherlands & -32.1 & 0.11 & -32.1 & 0.06 \\
\hline & $\# 7$ & UK & -27.9 & 0.11 & -28.0 & 0.09 \\
\hline & $\# 8$ & Netherlands & -29.0 & 0.15 & -29.1 & 0.13 \\
\hline & \#9 & Netherlands & -23.1 & 0.02 & -23.2 & 0.06 \\
\hline & \#10 & China & -29.5 & 0.05 & -29.4 & 0.01 \\
\hline & \#11 & China & -27.9 & 0.13 & -28.1 & 0.07 \\
\hline & \#12 & China & -29.8 & 0.05 & -29.9 & 0.09 \\
\hline & \#13 & China & -27.8 & 0.05 & -27.9 & 0.05 \\
\hline & \#14 & China & -27.6 & 0.09 & -27.7 & 0.08 \\
\hline
\end{tabular}




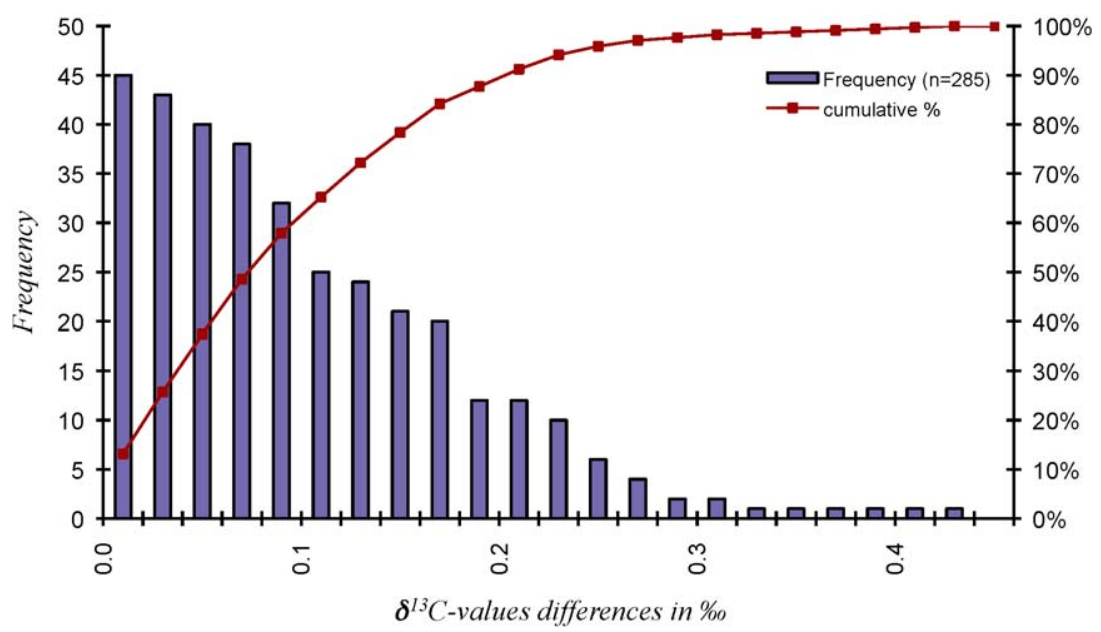

Fig. 3. Intravariability: distribution of differences in $\delta^{13} \mathrm{C}$-values of GBL between pairs of samples from the same batch.

step. Given the relatively low cost for producing GBL at the industrial level, it may be expected that the organic precursors are mainly originating from petroleum and related organic matter. It was reported by Yeh and Epstein [38] that the $\delta^{13} \mathrm{C}$-values of 114 petroleum samples were ranging from -23 to $-33 \%$ depending on their geographic age or location; more importantly, the study pointed out that compound-grouped fractions did not show significant isotope fractionation with respect to the crude oil.

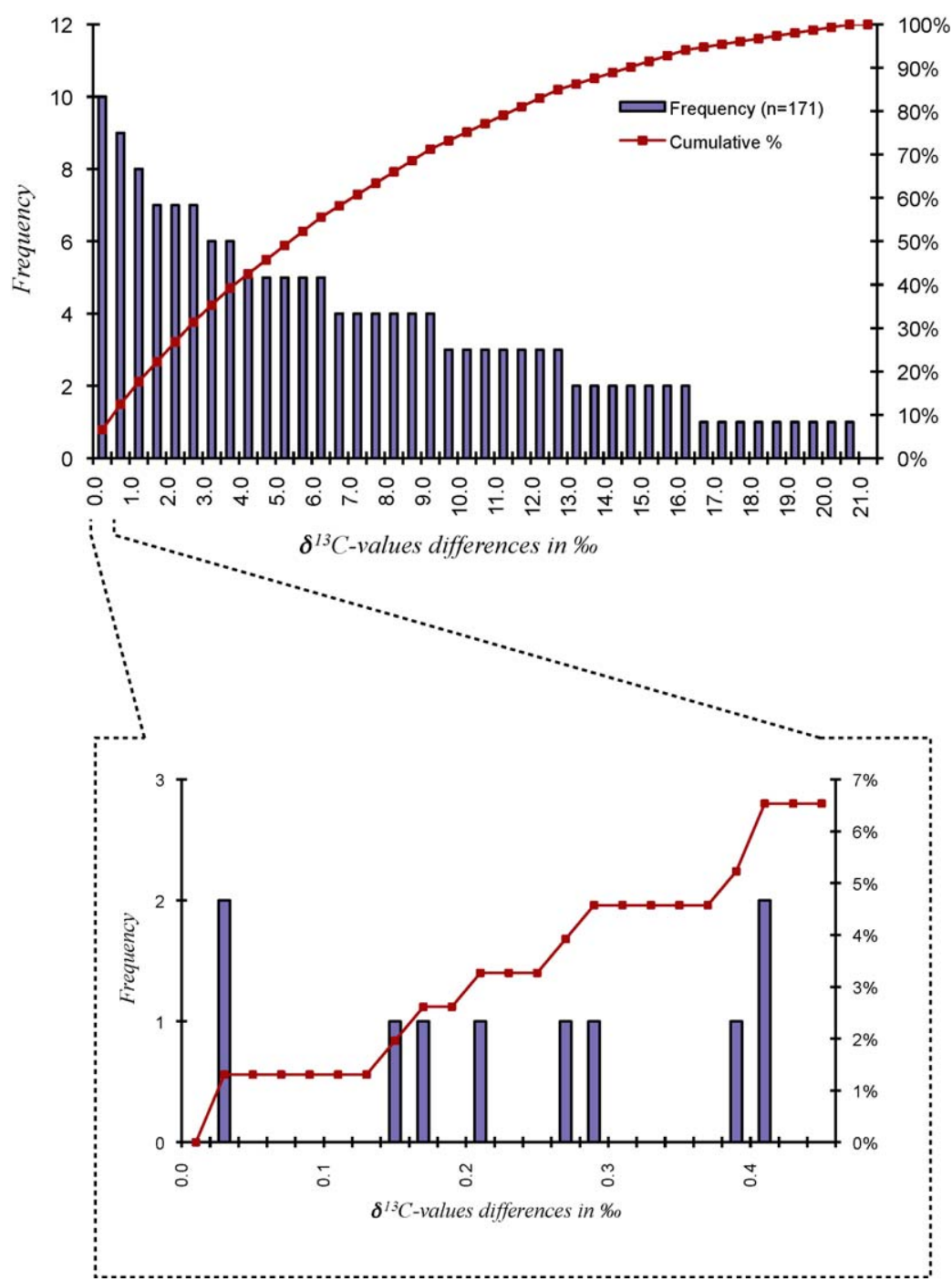

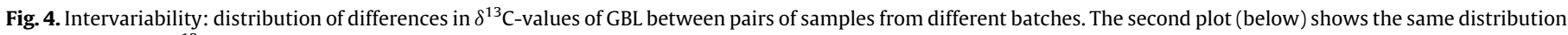
for differences in $\delta^{13} \mathrm{C}$-values between 0.0 and $0.4 \%$; this corresponds to the range of the distribution of intra variability illustrated in Fig. 3 . 
Considering that the isotopic signature of crude oil feedstocks is conserved throughout the chemical process, these data may not account for $\delta^{13} \mathrm{C}$-values less than $-40 \%$ assessed for some of the GBL samples (Table 1). Likewise, n-butane used as a feedstock for the manufacture of maleic anhydride is not likely to induce large variation in the carbon isotopic compositions of bulk GBL [39]. In contrast, the kinetic isotope effect on the reactions to produce GBL may contribute significantly to the isotope distribution observed herein. Non-quantitative organic reactions characterized by incomplete conversion of the reactant containing the carbon bond involved in the rate determining step is susceptible to induce an isotope fractionation at that specific carbon position [40]. Therefore, it may be hypothesized that an isotope fractionation occurred during the manufacturing process of GBL samples (for instance GBL\#2, GBL\#3 and GBL\#5), owing to the unusual ${ }^{13} \mathrm{C}$ depletion $(\sim-45 \%)$ observed for these samples.

Potential of IRMS to infer the source of GBL seizures has been evaluated in a next step. This has been done by assessing the interand intra-variabilities of the $\delta^{13} \mathrm{C}$-values. The intra-variability was calculated by reporting the differences in the carbon isotope ratio between each of the six replicates of the 19 GBL bulk (285 values). Concerning the inter-variability, the differences in the carbon isotope ratio means between the $19 \mathrm{GBL}$ standards (171 values) have been measured. The distributions of the intra- and intervariabilities were compared using a visual plot (Figs. 3 and 4) and a ROC curve (Receiver Operating Characteristic) leading to a high discrimination between the two populations (area under the curve of 0.991).

These results, associated with an accuracy of less than $0.3 \%$ and a high repeatability, suggest that the discriminating ability of IRMS is sufficiently high to assess the source of a GBL sample. In order to test this approach, future work will be focused on the analyses of GBL samples from police seizures.

\section{Conclusions}

A method for the determination of the carbon isotopes content of GBL by GC/C/IRMS was developed and its accuracy and robustness were assessed. Hence, this method has been applied at 6 months interval to $19 \mathrm{GBL}$ bulk lots purchased from diverse chemical providers and internet retailers of different countries, showing a high repeatability. The wide range of $\delta^{13} \mathrm{C}$-values (from -23.12 to $-45.78 \%$ ) enlightened the broad variability in stable isotope profiles that characterizes GBL batches from different sources and origins. In accordance with previously published research conducted with several solvents, it has been verified that distillation which could take place in the purification process of GBL production does not involve isotope fractionation and thus does not significantly affect $\delta^{13} \mathrm{C}$-values.

The results obtained so far demonstrate the feasibility of a forensic approach to discriminate between samples of different origins by means of statistical analysis and further link a specimen to a definite source or draw inference on a possible common source of two samples. Considering the measurements performed, variations in the ${ }^{13} \mathrm{C} /{ }^{12} \mathrm{C}$ ratio of $\mathrm{GBL}$ are likely to result from the combination of the stable isotope profile of the chemicals used in the manufacturing processes and the broad diversity of the synthesis pathways. In order to study further the influence of these parameters, isotopic profiling of GBL samples manufactured in a same industrial plant will be achieved to put forth potential isotope fractionation.

\section{Acknowledgements}

This study was supported by the Swiss National Science Foundation (Funds No. 205121_122309/1 and No. 106011_11
7413/1). The authors would like to thank L. Besson and T. Walter for scientific advice.

\section{References}

[1] M.L. Morgan, The rapidly changing world of 1,4-butanediol, Chem. Ind. 3 (1997) 166-168.

[2] F.J. Couper, L.J. Marinetti, $\gamma$-Hydroxybutyrate (GHB)-effects on human performance and behavior, Forensic Sci. Rev. 14 (2002) 102-121, Available at: http:// www.ndaa.org/pdf/ntlc_ghb.pdf (accessed June 18.06.09).

[3] China Chemical Reporter, GBL will be oversupply, Market Report: polymer, November 6, 2006.

[4] L.P. Kyrides, F.B. Zienty, Dehydrogenation of 1,4-pentanediol, J. Am. Chem. Soc. 68 (1946) 1385.

[5] N. Ichikawa, S. Sato, R. Takahashi, T. Sodesawa, K. Inui, Dehydrogenative cyclization of 1,4-butanediol over copper-based catalyst, J. Mol. Catal. A: Chem. 212 (2004) 197-203.

[6] J. Huang, W.-L. Dai, H. Li, K. Fan, Au/TiO 2 as high efficient catalyst for the selective oxidative cyclization of 1,4-butanediol to $\gamma$-butyrolactone, J. Catal. 252 (2007) 69-76.

[7] T. Haas, B. Jaeger, R. Weber, S.F. Mitchell, C.F. King, New diol processes: 1,3propanediol and 1,4-butanediol, Appl. Catal. A: Gen. 280 (2005) 83-85.

[8] C. Ohlinger, B. Kraushaar-Czarnetzki, Improved processing stability in the hydrogenation of dimethyl maleate to $\gamma$-butyrolactone, 1,4-butanediol and tetrahydrofuran, Chem. Eng. Sci. 58 (2003) 1453-1461.

[9] Y. Hara, H. Kusaka, H. Inagaki, K. Takahashi, K. Wada, A novel production of $\gamma$ butyrolactone catalyzed by ruthenium complexes, J. Catal. 194 (2000) 188197.

[10] Y.-L. Zhu, J. Yang, G.-Q. Dong, H.-Y. Zheng, H.-H. Zhang, H.-W. Xiang, Y.-W. Li, An environmentally benign route to $\gamma$-butyrolactone through the coupling of hydrogenation and dehydrogenation, A, Catal. B: Environ. 57 (2005) 183- 190.

[11] G.L. Castiglioni, M. Ferrari, A. Guercio, A. Vaccari, R. Lancia, C. Fumagalli, Chromium-free catalysts for selective vapor phase hydrogenation of maleic anhydre to $\gamma$ butyrolactone, Catal. Today 27 (1996) 181-186.

[12] L.M. Berkowitz, P.N. Rylande, Use of ruthenium tetroxide as a multi-purpose oxidant, J. Am. Chem. Soc. 80 (1958) 6682-6684.

[13] GHB and Its Precursor GBL: An Emerging Trend Case Study, European Monitoring Centre for Drugs and Drug Addiction, Lisbon, 2008.

[14] F. Sjöqvist, M. Garle, A. Rane, Use of doping agents, particularly anabolic steroids, in sports and society, Lancet 371 (2008) 1872-1882.

[15] M.E Liechti, H. Kupferschmidt, $\gamma$-Hydroxybutyrate (GHB) and $\gamma$-butyrolactone (GBL): analysis of overdose cases reported to the Swiss Toxicological Information Centre, Swiss Med. Wkly 134 (2004) 534-537.

[16] R.H. Roth, N.J. Giarman, Evidence that central nervous system depression by 1,4butanediol is mediated through a metabolite, gamma-hydroxybutyrate, Biochem. Pharmacol. 17 (1968) 735-739.

[17] R.H. Roth, N.J. Giarman, Natural occurrence of gamma-hydroxybutyrate in mammalian brain, Biochem. Pharmacol. 19 (1970) 1087-1093.

[18] D. Lenz, M.A. Rothschild, L. Kröner, Intoxications due to ingestion of gammabutyrolactone: organ distribution of gamma-hydroxybutyric acid and gammabutyrolactone, Ther. Drug Monit. 30 (2008) 755-761.

[19] K. Mickelsson, Gamma-butyrolactone (GBL) and 1,4-Butanediol (1,4-BD) as Industrial Chemicals and Drugs of Abuse, Can They be Regulated? National Institute of Public Health, 2005 http://www.fhi.se (accessed 24.06.09).

[20] S. Benson, C. Lennard, P. Maynard, C. Roux, Forensic applications of isotope ratio mass spectrometry-a review, Forensic Sci. Int. 157 (2006) 1-22.

[21] H. Craig, Isotopic standards for carbon and oxygen and correction factors for mass-spectrometric analysis of carbon dioxide, Geochim. Cosmochim. Acta 12 (1957) 133-149.

[22] WADA Technical Document-TD2003IDCR, World Anti-Doping Agency, 2007 http://www.wada-ama.org/rtecontent/document/criteria_1_2.pdf (accessed 26.08.07).

[23] T. Fawcett, An introduction to ROC analysis, Pattern Recogn. Lett. 27 (8) (2006) 861-874.

[24] P. Esseiva, S. Ioset, F. Anglada, L. Gasté, O. Ribaux, P. Margot, A. Gallusser, A Biedermann, Y. Specht, E. Ottinger, Forensic drug intelligence: an important tool in law enforcement, Forensic Sci. Int. 167 (2007) 247-254.

[25] L. Dujourdy, V. Dufey, F. Besacier, N. Miano, R. Marquis, E. Lock, L. Aalberg, S. Dieckmann, F. Zrcek, J.S. Bozenko Jr., Drug intelligence based on organic impurities in illicit MA samples, Forensic Sci. Int. 177 (2008) 153-161.

[26] S. Lociciro, P. Esseiva, P. Hayoz, L. Dujourdy, F. Besacier, P. Margot, Cocaine profiling for strategic intelligence, a cross-border project between France and Switzerland. Part II. Validation of the statistical methodology for the profiling of cocaine, Forensic Sci. Int. 177 (2008) 199-206.

[27] P. Esseiva, L. Dujourdy, F. Anglada, F. Taroni, P. Margot, A methodology for illicit heroin seizures comparison in a drug intelligence perspective using large databases, Forensic Sci. Int. 132 (2003) 139-152.

[28] J.R. Ehleringer, J.F. Casale, M.J. Lott, V.L. Ford, Tracing the geographical origin of cocaine, Nature 408 (2000) 311-312.

[29] F. Palhol, C. Lamoureux, M. Chabrillat, N. Naulet, $15 \mathrm{~N} / 14 \mathrm{~N}$ isotope ratio and statistical analysis: an efficient way of linking seized Ecstasy tablets, Anal. Chim. Acta 510 (2004) 1-8.

[30] N. Gentile, R. Siegwolf, O. Delémont, Study of isotopic variations in black powder: reflection on the use of stable isotopes in forensic science for source inference, Rapid Commun. Mass Spectrom. 23 (2009) 2559-2567. 
[31] C. Saudan, M. Augsburger, P. Mangin, M. Saugy, Carbon isotopic ratio analysis by gas chromatography/combustion/isotope ratio mass spectrometry for the detection of gamma-hydroxybutyric acid (GHB) administration to humans, Rapid Commun. Mass Spectrom. 21 (2007) 3956-3962.

[32] W. Meier-Augenstein, Applied gas chromatography coupled to isotope ratio mass spectrometry, J. Chromatogr. A 842 (1999) 351-371.

[33] J. Schmitt, B. Glaser, W. Zech, Amount-dependent isotopic fractionation during compound-specific isotope analysis, Rapid Commun. Mass Spectrom. 17 (2003) 970-977.

[34] C.M. Lock, W. Meier-Augenstein, Investigation of isotopic linkage between precursor and product in the synthesis of a high explosive, Forensic Sci. Int. 179 (2008) 157-162.

[35] N. NicDaeid, W. Meier-Augenstein, Feasibility of source identification of seized street drug samples by exploiting differences in isotopic composition at natural abundance level by GC/MS as compared to isotope ratio mass spectrometry (IRMS), Forensic Sci. Int. 174 (2008) 259-261.

[36] P. Baertchi, W. Kuhn, H. Kuhn, Fractionation of isotopes by distillation of some organic substances, Nature 171 (1953) 1018-1020.

[37] D.C. Bradley, Fractionation of isotopes by distillation of some organic substances, Nature 173 (1954) 260-261.

[38] H.-W. Yeh, S. Epstein, Hydrogen and carbon isotopes of petroleum and related organic matter, Geochim. Cosmochim. Acta 45 (1981) 753-762.

[39] J. Dai, X. Xia, S. Qin, J. Zhao, Origins of partially reversed alkane $\delta^{13} \mathrm{C}$ values for biogenic gases in China, Org. Geochem. 35 (2004) 405-411.

[40] G. Rieley, Derivatization of organic compounds prior to gas chromatographycombustion-isotope ratio mass spectrometry analysis: identification of isotope fractionation processes, Analyst 119 (1994) 915-919. 